\title{
TWINNING IN TWIN PEDIGREES
}

\author{
BY \\ J. A. H. WATERHOUSE \\ From the Department of Medical Statistics, University of Birmingham
}

\section{INTRODUCTION}

Since the implementation of the Population (Statistics) Act (1938) on July 1, 1938, there has been available for England and Wales information concerning the age of the mother, and the number of previous children born to her, for all births completely registered. Unfortunately the number of previous children does not give exactly the parity of a birth, as some of the previous children may have resulted from multiple births. As the proportion of multiple maternities to all maternities seldom exceeds 2 per cent., the consequent lack of precision is not likely to lead to serious error in most applications, though from the point of view of this enquiry it is of greater significance. Included in the Registrar-General's Statistical Review for 1938 (Tables. Part II: Civil) there is a discussion of the first half-year's experience as it affects the problem of twinning. The numbers are frequently too small to provide more than an indication of the pattern of twin production, but since that time data for ten more years have been published.

\section{Twin Incidence by Maternal Age AND Parity}

Table I exhibits, for quinquennial maternal age groups and for numbers of previous children up to nine, the numbers of legitimate twin maternities per thousand total legitimate maternities. The proportion of twin maternities increases with

TABLE I

Legitimate Twin Maternities per Thousand Legitimate Maternities, by Age of Mother and Number of Previous Children

ENGLAND AND Wales, July 1938-December 1948*

(Registrar-General's figures)

\begin{tabular}{|c|c|c|c|c|c|c|c|c|c|c|c|}
\hline \multirow{2}{*}{ Age of Mother } & \multicolumn{11}{|c|}{ Number of Previous Children } \\
\hline & 0 & 1 & 2 & 3 & 4 & 5 & 6 & 7 & 8 & 9 & Total \\
\hline $\begin{array}{c}<20 \\
20-24 \\
25-29 \\
30-34 \\
35-39 \\
40-44 \\
45-49\end{array}$ & $\begin{array}{r}6 \cdot 3 \\
8 \cdot 2 \\
10 \cdot 6 \\
12 \cdot 4 \\
13 \cdot 6 \\
10 \cdot 0 \\
11 \cdot 3\end{array}$ & $\begin{array}{r}7 \cdot 2 \\
9 \cdot 3 \\
11 \cdot 7 \\
14 \cdot 0 \\
15 \cdot 4 \\
11 \cdot 8 \\
6 \cdot 4\end{array}$ & $\begin{array}{r}8 \cdot 9 \\
10 \cdot 7 \\
13 \cdot 0 \\
15 \cdot 7 \\
16 \cdot 5 \\
12 \cdot 3 \\
4 \cdot 2\end{array}$ & $\begin{array}{r}1 \overline{11 \cdot 3} \\
13 \cdot 9 \\
16 \cdot 4 \\
18 \cdot 3 \\
12 \cdot 5 \\
6 \cdot 8\end{array}$ & $\begin{array}{r}-\overline{11 \cdot 9} \\
14 \cdot 5 \\
18 \cdot 0 \\
19 \cdot 4 \\
14 \cdot 1 \\
5 \cdot 4\end{array}$ & $\begin{array}{r}- \\
14 \cdot 5 \\
17 \cdot 8 \\
20 \cdot 0 \\
12 \cdot 8 \\
7 \cdot 4\end{array}$ & $\begin{array}{l}- \\
\overline{16 \cdot 4} \\
18 \cdot 1 \\
20 \cdot 1 \\
15 \cdot 0 \\
6 \cdot 0\end{array}$ & $\begin{array}{l}- \\
- \\
14 \cdot 6 \\
18 \cdot 5 \\
21 \cdot 9 \\
15 \cdot 1 \\
6 \cdot 8\end{array}$ & $\begin{array}{r}- \\
- \\
\overline{18 \cdot 8} \\
20 \cdot 7 \\
17 \cdot 3 \\
8 \cdot 5\end{array}$ & $\begin{array}{r}- \\
\overline{-} \\
17 \cdot 0 \\
18 \cdot 7 \\
14 \cdot 2 \\
7 \cdot 7\end{array}$ & $\begin{array}{r}6 \cdot 4 \\
8 \cdot 7 \\
11 \cdot 6 \\
14 \cdot 6 \\
16 \cdot 8 \\
13 \cdot 1 \\
6 \cdot 8\end{array}$ \\
\hline All Ages & $9 \cdot 8$ & $12 \cdot 2$ & $14 \cdot 3$ & $15 \cdot 6$ & $17 \cdot 1$ & $17 \cdot 2$ & $17 \cdot 9$ & $18 \cdot 6$ & $18 \cdot 7$ & $16 \cdot 1$ & $12 \cdot 2$ \\
\hline
\end{tabular}

* Rates based on less than ten twin maternities are excluded from this Table. 
the age of the mother to a peak in the age group 35-39, falling thereafter rather more steeply than it rose; this general form is followed very closely for each number of previous children - or, as we may say with risk of only small error, for each birth rank (see Fig. 1). Thus the effect of birth rank is merely to cause a vertical displacement of the curve, which summarizes the effect for all birth ranks. Distributions by maternal age of a pattern similar to this have been shown by most writers on the vital statistics of twinning, though rarely simultaneously for birth rank (see Jenkins, 1927: Table VI).

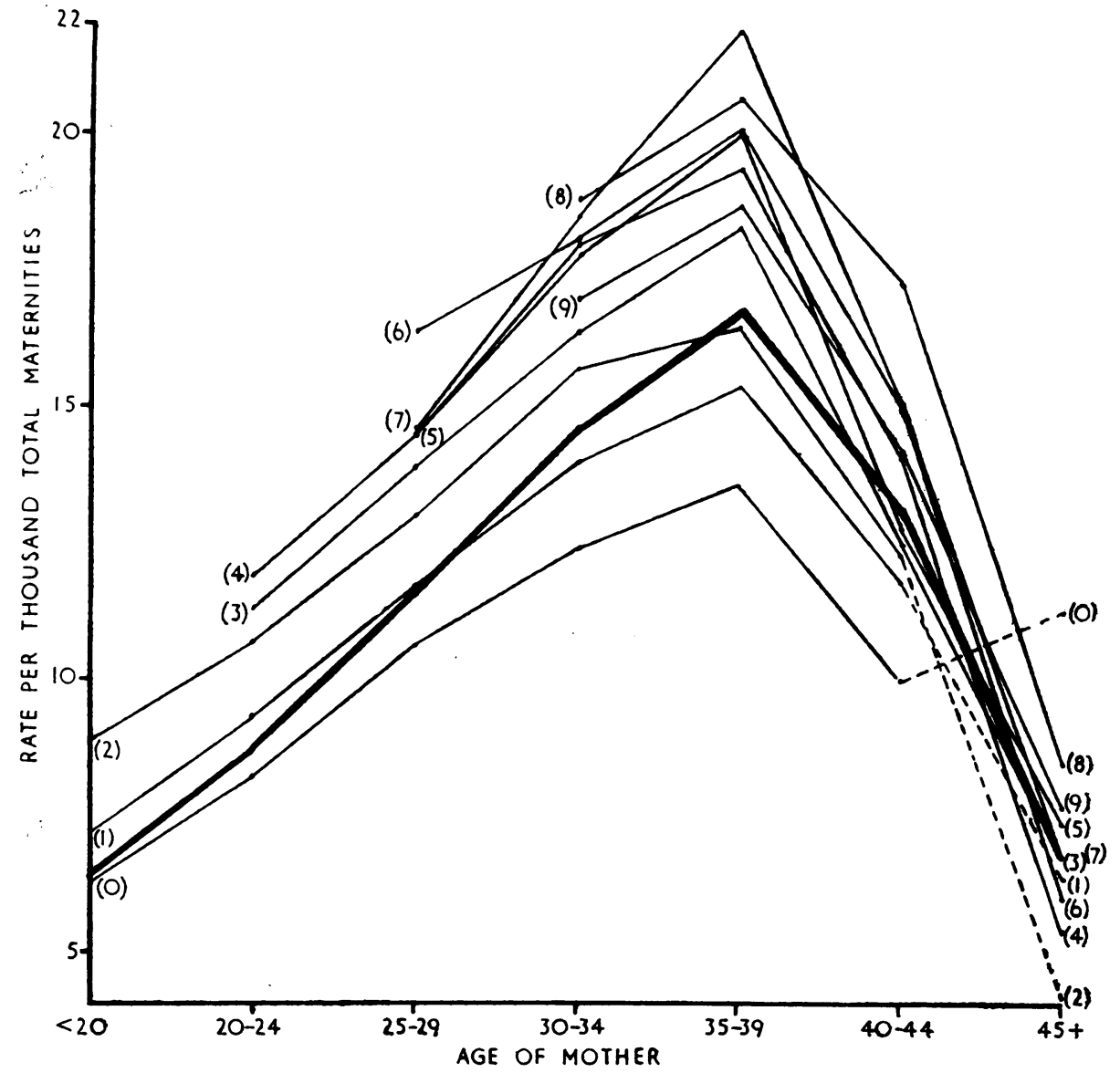

FIG. 1.-Twin maternities per thousand total maternities, by age of mother.

Fig. 2 displays the rates of Table I by number of previous children, for each quinquennial maternal age group and for all ages, and shows in general a steady rise to a maximum at about the eighth birth rank (seven previous children). Again there is only a vertical displacement between the curves for different age groups, each curve being of approximately the same shape. 
3. INCIDENCE OF MONOZYGOUS AND DizYgous Twinning

Weinberg's method of obtaining the relative proportions of monozygous and dizygous twins assumes a sex ratio of $1: 1$, so that amongst the sex groups MM, MF, and FF, dizygous twin pairs would be distributed in the proportions $\frac{1}{4}: \frac{1}{2}: \frac{1}{4}$. Since all unlike-sex twin pairs must be dizygous in origin, and since on Weinberg's assumption the numbers of like- and unlike-sex dizygous twin pairs are equal, the number of monozygous pairs of twins is obtained by subtracting from the total of like-sex pairs the number of unlike-sex pairs.

On the assumption of a sex ratio different from unity but the same for both monozygous and dizygous pairs,

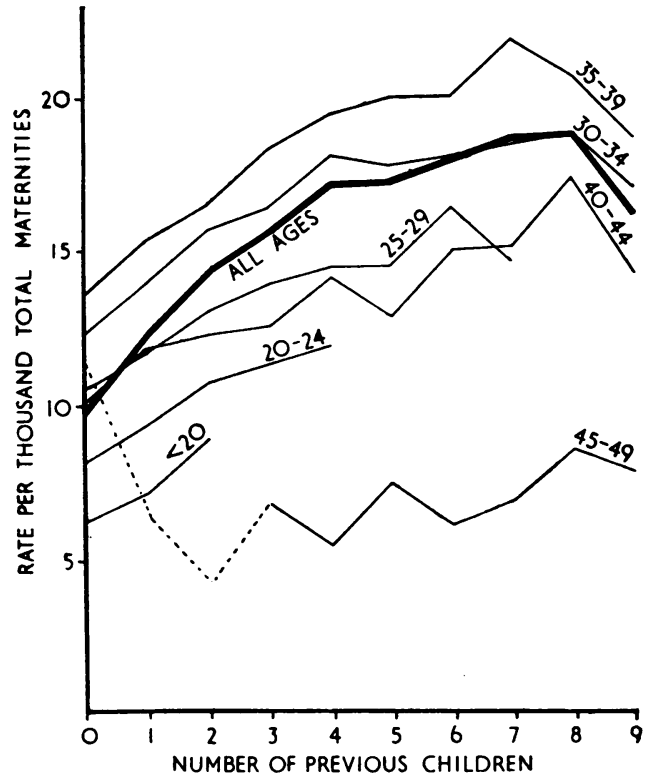

FIG. 2.-Twin maternities per thousand total maternities, by number of previous children. and therefore calculable from the data, a slightly different proportion of monozygous to dizygous pairs is obtainable. Denoting the proportions in the sex groups thus: $\mathrm{MM}-a ; \mathrm{MF}-2 b ; \mathrm{FF}-c$; so that $a+2 b+c=1$, we have for $p$, the observed proportion of male births:

$$
p=a+b .
$$

The dizygous twins will be distributed among the sex groups as

$$
p^{2}: 2 p(1-p):(1-p)^{2}
$$

and if we denote by $x$ the proportion of dizygous twins, and by $(1-x)$ the proportion of monozygous twins, we shall have the sex groups made up as follows:

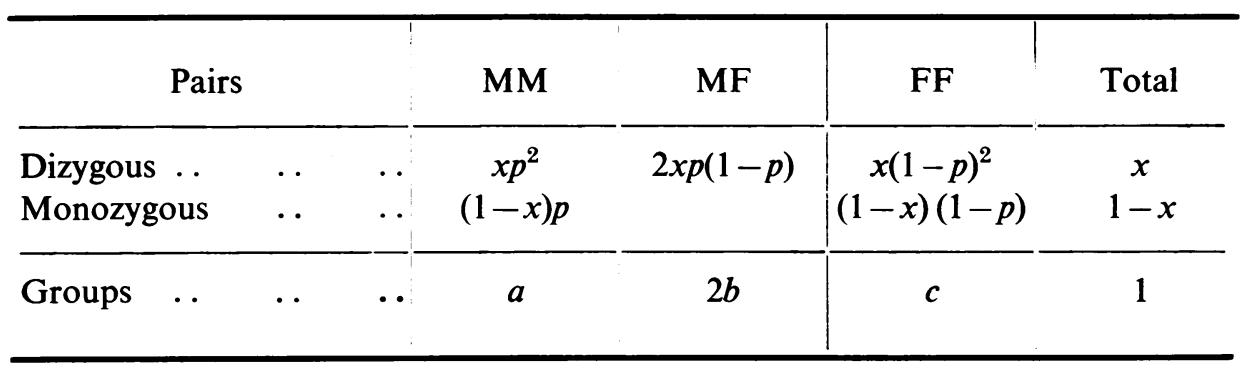

from which we obtain:

$$
x=\frac{b}{p(1-p)}=\frac{b}{(a+b) \overline{(b+c)}}
$$

* Formulae for estimating $p$ and $x$ are also those derivable by the method of maximum likelihood. 
In Weinberg's method, $p$ is assumed to be $\frac{1}{2}$, which gives the value $4 b$ for $x$. We may discover the difference in the estimates between the two methods by setting

$$
p=\frac{1}{2}(1+h) \text {, }
$$

where $h$ represents the proportionate difference of the empirical fraction from $\frac{1}{2}$.

Then we have

$$
x=\frac{4 b}{(1+h)(1-h)}=\frac{4 b}{1-h^{2}}
$$

and also, from

$$
\begin{aligned}
\frac{1}{2}(1+h) & =p=a+b, \\
h & =2(a+b)-1=a-c,
\end{aligned}
$$

so that we may write approximately (for $h$ small):

$$
x=4 b\left[1+(a-c)^{2}\right]
$$

A third method of estimation suggests itself in view of the low sex ratio of twin births $(50.87$ per cent. male)* in comparison with single births $(51.52$ per cent. male)*. If, as this fact implies, there is a disproportionate loss of males by abortion from twin pregnancies, reducing the resultant sex ratio at 28 weeks and above, it may be preferable to use the sex ratio for all births in calculating the relative proportions of monozygous and dizygous twins. If we denote the proportion of males in all births by $m$, that of females by $f$ (so that $m+f=1$ ), and the proportion of dizygous twins calculated on this assumption by $y$, we obtain in a manner exactly analogous to that used above:

or approximately (for $m-f$ small):

$$
y=\frac{b}{m(1-m)}=\frac{b}{m \cdot f}
$$

$$
y=4 b\left[1+(m-f)^{2}\right]
$$

For the $10 \frac{1}{2}$-year period under review in this paper, $m-f$ for the whole period is about 0.03 , giving rise to a deviation of the order of 0.1 per cent. between the indices computed by Weinberg's method or by the formula of equation (ii). For individual years the deviation between the indices obtained from equations (i) or (ii) and that from Weinberg's formula does not exceed 0.2 per cent. For any further subdivisions of these periods the error may well be larger as between the different methods of computation, but at the same time the error of estimation, based on smaller numbers, also increases and thus renders such discrimination insignificant. Moreover, the differential impact on the sexes of abortion and stillbirth risks may unduly distort the relative proportions obtained by the second method, while Weinberg's method to some extent compensates for such imbalance. For these reasons, though the second and third methods may possess some theoretical advantages, the simpler method of Weinberg has been used below to calculate the relative proportions of monozygous and dizygous twins.

Table II (see also Fig. 3) shows by maternal age the incidence of monozygous and dizygous twin maternities per thousand total maternities. The incidence of monozygous twins is virtually independent of maternal age, rising from $3 \cdot 2$ to 3.8 per 1,000; the incidence of dizygous twins rises sharply from under 3 per 1,000 (mothers under 20) to 13 per 1,000 (mothers aged 35-39), and then falls to 3 per

\footnotetext{
* England and Wales, 10t years 1938-1948: live births and stillbirths.
} 
TABLE II

InCidence of Monozygous and Dizygous Twin Maternities Per Thousand Total Maternities,

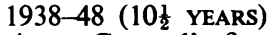

(Registrar-General's figures)

\begin{tabular}{cc:cc}
\hline Age of Mother & Monozygous & Dizygous & Total \\
\hline$<20$ & $3 \cdot 24$ & $2 \cdot 92$ & $6 \cdot 16$ \\
$20-24$ & $3 \cdot 32$ & $5 \cdot 32$ & $8 \cdot 64$ \\
$25-29$ & $3 \cdot 39$ & $8 \cdot 26$ & $11 \cdot 65$ \\
$30-34$ & $3 \cdot 62$ & $11 \cdot 02$ & $14 \cdot 64$ \\
$35-39$ & $3 \cdot 68$ & $13 \cdot 22$ & $16 \cdot 90$ \\
$40-44$ & $3 \cdot 63$ & $9 \cdot 44$ & $13 \cdot 07$ \\
45 and over & $3 \cdot 84$ & $3 \cdot 13$ & $6 \cdot 97$ \\
\hline All Ages & $3 \cdot 47$ & $8 \cdot 65$ & $12 \cdot 12$ \\
\hline
\end{tabular}

1,000 (mothers aged 45-49). These observations are consistent with earlier reports (e.g. Jenkins, 1927; Jenkins and Gwin, 1940; Yerushalmy and Sheerar, 1940), but demonstrate the relationship in a more regular way.

It is at once apparent that the comparison of gross rates of twin production is invalid unless accompanied by the distribution by maternal age of all births; for a relation of the kind depicted in Fig. 3, if it is descriptive of an underlying physiological effect, calls for age standardization in comparing rates. That a physiological relationship exists between twin production-chiefly that of dizygous twinning-and maternal age, at least among peoples of European origin, is evidenced by their statistics. In Japan, Komai and Fukuoka (1932) quote $3 \cdot 1$ per 1,000 and $3 \cdot 8$ per 1,000 from different Japanese sources for the monozygous rates, the corresponding dizygous rates being 2.6 per 1,000 and 1.9 per 1,000 . Thus the monozygous rates are consistent

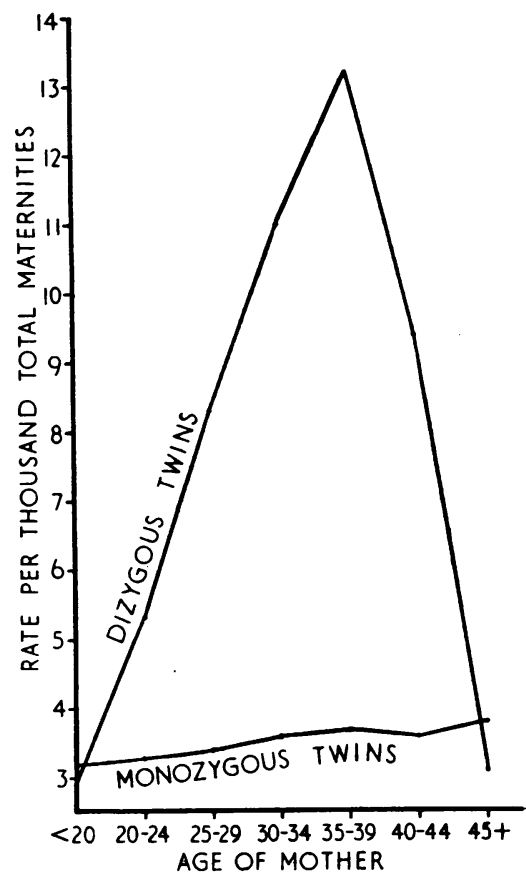

Fig. 3.-Incidence of monozygous and dizygous twin maternities per thousand total maternities, by age of mother. with those here given for England and Wales, but the dizygous rates are lower. Since it is customary in Japan to have children very early in life, it is interesting to examine the trend of the dizygous rate in England and Wales at maternal ages under 20, and to note that the same age incidence relationship of dizygous twinning may be applicable.

Table III shows the total twinning rate for each year of age from 16 to 19 inclusive for the 101 -year period 1938-48 in England and Wales. The RegistrarGeneral does not give the numbers of twin maternities by individual years of age 
but we have obtained them by subtracting the number of maternities from the number of births for each age, assuming the excess to consist only of twins. This assumption is not fully justified because the Registrar-General quotes for the whole period seven triplet maternities at ages under 20. Discounting this fact which would only lower the rates obtained in one or more years of age, it is evident that the total twinning rate continues to decrease with maternal age for ages under 20 (cf. Table II). In fact at 16 years, if the monozygous rate is still of the order of 3 per 1,000 , then it is more than twice as great as the dizygous rate.

TABLE III

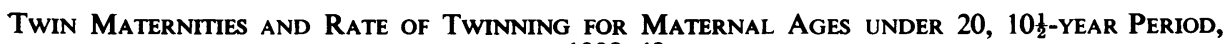
$1938-48$

(Registrar-General's figures)

\begin{tabular}{llllll|l|l|l|l|l|l}
\hline Age of Mother &.. &. & $\ldots$ & $\ldots$ &. & 14 & 15 & 16 & 17 & 18 & 19 \\
\hline Twin Maternities &.. & $\ldots$ & $\ldots$ & $\ldots$ & $\ldots$ & 3 & 10 & 39 & 182 & 487 & 1,006 \\
\hline Rate per Thousand Total Maternities & & $\ldots$ & - & - & $4 \cdot 1$ & $5 \cdot 6$ & $6 \cdot 0$ & 6.6 \\
\hline
\end{tabular}

Figs 1 and 2 alone would suffice to emphasize the necessity of age standardization; indeed, taken in conjunction with the constancy of the monozygous rate, they suggest that standardization by birth rank is also necessary, but it is impossible to confirm this from the data provided by the Registrar-General for England and Wales.

\section{TRIPLET BirthS}

The well-known "Hellin's Law" for the relative frequencies of successive orders of multiple births, if applied as by Jenkins (Jenkins, 1927; Jenkins and Gwin, 1940) to each maternal age group, could be interpreted as evidence of the independence of the two modes of twin production, given propitious circumstances which may be either genetic or environmental. For, assuming that the mechanisms producing monozygous and dizygous twins do indeed act independently with frequencies $u$ and $v$ respectively, the chance that the same agencies may act simultaneously to produce triplet births would be:

$$
(u+v)^{2}=u^{2}+2 u v=v^{2}
$$

the successive terms of which, following Jenkins and Gwin, would represent the proportionate frequencies of monozygous, dizygous (i.e. the simultaneous occurrence of monozygous and dizygous twinning), and trizygous triplets. The relative frequencies of these types of triplets may well be distorted at birth by differential mortality in utero according either to sex or to the mode of origin. Jenkins and Gwin, who were unable to include all stillbirths in their computations, obtained an estimate of the in utero survival rate by applying the rates calculated from twins to the observed triplet sex-groups, and by finding the divergence between the observed and expected values.

If we proceed as did Jenkins and Gwin and calculate the regression of the 
observed triplet rates by maternal age on the squared twin rates, we obtain the following equations: $\quad y=9 \cdot 01+0.588 x$$$
y=7 \cdot 42+0 \cdot 596 x
$$

Here $y$ is the number of triplet maternities per million total maternities (live and still), $x$ the square of the total rate of twinning (total twin maternities per thousand total maternities, live and still), and equation ( $a$ ) represents the unweighted regression, (b) that weighted by the respective numbers of triplet maternities in each maternal age group. The difference between the two equations is small, except possibly in the constant term, but the weighted equation has more to commend it from the theoretical standpoint, and we shall use it in preference. In our notation, the equation of Jenkins and Gwin is:

$$
y=13 \cdot 18+0 \cdot 656 x
$$

which has both a larger constant term and a larger regression coefficient than our equations.

We may account for the value of the constant in equation $(b)$ as a part of the monozygous rate and then regard the regression coefficient as measuring the in utero survival rate of dizygous and trizygous triplets as against that for dizygous twins, again following Jenkins and Gwin, or we may consider that the equation indicates a lack of independence between the two types of twinning, and that the assumptions underlying our derivation are not fully justified. For in the notation used above, $\quad x=u^{2}+2 u v+v^{2}$,

and $u$ is the rate of monozygous twin-production which is nearly constant over all maternal age groups, so that we may associate together the first two terms as representing the rate of monozygous triplet production, independent of maternal age. Thus: $\quad y=\left(7 \cdot 42+0 \cdot 596 u^{2}\right)+0 \cdot 596\left(2 u v+v^{2}\right)$

Adopting this method, and putting for $u$ its value calculated from twinning rates, we obtain for the production of monozygous triplets a rate in excess of $u^{2}$. Such an outcome appears unlikely, for it would imply either that spontaneous division of a single fertilized ovum at some stage of its development into three resultant embryos occurs rather more frequently than probability dictates, or that monozygous triplet embryos are more viable not only than other types of triplets but than monozygous twins, or-what amounts to a different aspect of the lastthat the monozygous twin rate should be higher than that actually observed. This latter follows if we use the first term in parenthesis in equation $(d)$ to estimate $u$, the rate of monozygous twinning, by assuming no increased risk of mortality among triplet pregnancies but that the constant, monozygous, rate of triplet production is equal to the square of the rate of monozygous twinning. . Then we have:

$$
7 \cdot 42+0 \cdot 596 u^{2}=u^{2}
$$

which yields a value for $u$ of about $4 \cdot 3$ per 1,000 , a rate rather in excess of any reported for monozygous twinning.

On the other hand, the discrepancy may well be due to factors affecting the dizygous or trizygous rates (such as that it is rarer than expected on the assumption of randomness for three ova to be released almost simultaneously), or it may be 
that there exists some mutually inhibitory effect on the simultaneous occurrence of both forms of twinning. Comparing the upper pair of curves of Fig. 4, showing together the square of the twinning rate (upper curve) and the observed triplet rate plotted on a logarithmic scale against maternal age, it is apparent that the difference between them (i.e. their ratio, since the scale is logarithmic) increases slightly with maternal age. Thus the regression coefficient in the equations above represents a mean of a ratio which is not precisely constant over the whole range of maternal age.

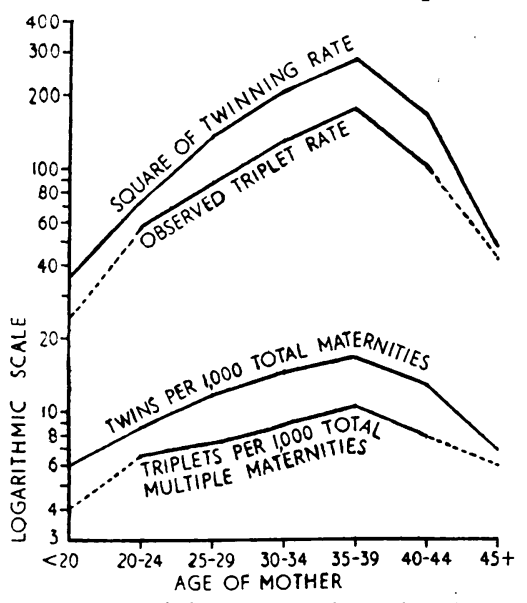

FIG. 4.-Triplet rates and Hellin's law.

The second pair of curves on Fig. 4 shows the rate of twin maternities per thousand total maternities by age of mother (upper curve) and the rate of triplet maternities per thousand total multiple maternities by age of mother (lower curve), offering another form of comparison between the twin and triplet rates. Again there is a slight increase in the disparity between the two curves with increasing maternal age, suggesting that the differential effect acts more heavily against dizygous and trizygous triplets than monozygous. The numbers of triplets available by maternal age for England and Wales, however, do not yet warrant a more mate thedistinctiveweights attach for triplet rates.

\section{SOURCE AND DESCRIPTION OF SAMPLE ENQUIRY}

In an attempt to supplement official statistics as a source of genetical information, the Department of Medical Statistics launched an appeal for the voluntary co-operation of twins in a national twin investigation. The national and local Press and the B.B.C. rendered every support in publicizing the project, and we obtained an index of 1,600 twin pairs. Numbers in the ensuing Tables are based on those index pairs for which information was complete and thus differ from the total.

To each of those who responded to the appeal we sent a questionnaire, the Family History Form, in which we asked for information respecting the index twins, their sibs, parents, and certain relatives. Concerning the twins themselves, we enquired their order of birth (partly for identification purposes and partly to determine any sex bias in the first-born of MF twin pairs), the interval between their birth, their age and sex-group, the age of the mother at their birth, and the relationship, if any, between the parents. Next we asked the number, ages, and sex of sibs (specifying half-sibs and step-sibs), and similar information respecting the sibs of the mother and father. For all these relatives, and for cousins, we asked the occurrence of twins to be specified in respect of sex-group, exact relationship, and age (now or at death). The form was designed to elicit the information in a manner at once systematic and straightforward. 
TABLE IV

Distribution of Twins by SeX-Group: for SAmple and for 10 $\frac{1}{2}$-Year Period (Registrar-General's figures)

\begin{tabular}{|c|c|c|c|c|c|c|c|c|}
\hline \multicolumn{5}{|c|}{ Sex-Group } & \multirow{2}{*}{$\begin{array}{c}\text { MM } \\
419 \\
29 \cdot 61\end{array}$} & \multirow{2}{*}{ 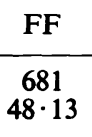 } & \multirow{2}{*}{$\begin{array}{c}\text { MF } \\
315 \\
22 \cdot 36\end{array}$} & \multirow{2}{*}{$\begin{array}{r}\text { All } \\
1,415 \\
100\end{array}$} \\
\hline $\begin{array}{l}\text { Numbers } \ldots \\
\text { Percentage .. }\end{array}$ & $\begin{array}{l}\ldots \\
\cdots\end{array}$ & $\begin{array}{l}\cdots \\
\cdots\end{array}$ & $\begin{array}{l}\cdots \\
\cdots\end{array}$ & $\begin{array}{l}\ldots \\
\cdots\end{array}$ & & & & \\
\hline \multicolumn{4}{|c|}{$E$ and $W$ Percentage ( $10 \frac{1}{2}$ years) } & . & $32 \cdot 49$ & $31 \cdot 37$ & $36 \cdot 14$ & 100 \\
\hline
\end{tabular}

\section{INDEX PAIRS}

Table IV compares the distribution by sex-group of 1,415 index pairs with the distribution of live-born twins in England and Wales for the 101 -year period, 1938-48. As anticipated, voluntary co-operation resulted in a sample which was not random; the MM group is slightly below expectation, while the FF and MF groups differ widely from their expectations. But we cannot fairly compare the distribution of twins at birth (as given for England and Wales) with a distribution of surviving pairs covering an age range of 80 years in our sample, since the mortality is greater for males than for females at every year of age, and this disproportion has been still greater in the past.

TABLE V

Distribution by Age for fach Sex-Group of Twin Pairs in Sample

\begin{tabular}{|c|c|c|c|c|c|c|c|c|}
\hline \multirow{2}{*}{ Age of Twins } & \multicolumn{2}{|c|}{$\mathbf{M M}$} & \multicolumn{2}{|c|}{ FF } & \multicolumn{2}{|c|}{ MF } & \multicolumn{2}{|c|}{ All } \\
\hline & No. & $\%$ & No. & $\%$ & No. & $\%$ & No. & $\%$ \\
\hline All Ages & 419 & $100 \cdot 0$ & 681 & $100 \cdot 0$ & 315 & $100 \cdot 0$ & 1,415 & $100 \cdot 0$ \\
\hline $\begin{array}{c}0-9 \\
10-19 \\
20-29 \\
30-39 \\
40-49 \\
50-59 \\
60-69 \\
70-79 \\
80 \text { and Over }\end{array}$ & $\begin{array}{r}135 \\
110 \\
69 \\
40 \\
39 \\
14 \\
6 \\
4 \\
2\end{array}$ & $\begin{array}{r}32 \cdot 2 \\
26 \cdot 3 \\
16 \cdot 5 \\
9 \cdot 5 \\
9 \cdot 3 \\
3 \cdot 3 \\
1 \cdot 4 \\
1 \cdot 0 \\
0 \cdot 5\end{array}$ & $\begin{array}{r}152 \\
157 \\
125 \\
106 \\
75 \\
38 \\
21 \\
7 \\
0\end{array}$ & $\begin{array}{r}22 \cdot 3 \\
23 \cdot 1 \\
18 \cdot 4 \\
15 \cdot 6 \\
11 \cdot 0 \\
5 \cdot 6 \\
3 \cdot 1 \\
1 \cdot 0 \\
-\end{array}$ & $\begin{array}{r}83 \\
77 \\
70 \\
34 \\
23 \\
11 \\
11 \\
6 \\
0\end{array}$ & $\begin{array}{r}26 \cdot 3 \\
24 \cdot 4 \\
22 \cdot 2 \\
10 \cdot 8 \\
7 \cdot 3 \\
3 \cdot 5 \\
3 \cdot 5 \\
1 \cdot 9 \\
\end{array}$ & $\begin{array}{r}370 \\
344 \\
264 \\
180 \\
137 \\
63 \\
38 \\
17 \\
2\end{array}$ & $\begin{array}{r}26 \cdot 1 \\
24 \cdot 3 \\
18 \cdot 7 \\
12 \cdot 7 \\
9 \cdot 7 \\
4 \cdot 5 \\
2 \cdot 7 \\
1 \cdot 2 \\
0 \cdot 1\end{array}$ \\
\hline
\end{tabular}

TABLE VI

Percentage Distribution by Sex-Group for each Age: from Sample

\begin{tabular}{|c|c|c|c|c|}
\hline Age Group & $\mathbf{M M}$ & FF & MF & All \\
\hline $\begin{array}{c}0-9 \\
10-19 \\
20-29 \\
30-39 \\
40-49 \\
50-59 \\
60-69 \\
70-79\end{array}$ & $\begin{array}{l}36 \cdot 5 \\
32 \cdot 0 \\
26 \cdot 1 \\
22 \cdot 2 \\
28 \cdot 5 \\
22 \cdot 2 \\
15 \cdot 8 \\
23 \cdot 5\end{array}$ & $\begin{array}{l}41 \cdot 1 \\
45 \cdot 6 \\
47 \cdot 4 \\
58 \cdot 9 \\
54 \cdot 7 \\
60 \cdot 3 \\
55 \cdot 3 \\
41 \cdot 2\end{array}$ & $\begin{array}{l}22 \cdot 4 \\
22 \cdot 4 \\
26 \cdot 5 \\
18 \cdot 9 \\
16 \cdot 8 \\
17 \cdot 5 \\
28 \cdot 9 \\
35 \cdot 3\end{array}$ & $\begin{array}{l}100 \\
100 \\
100 \\
100 \\
100 \\
100 \\
100 \\
100\end{array}$ \\
\hline All Ages & $29 \cdot 6$ & $48 \cdot 1$ & $22 \cdot 3$ & 100 \\
\hline
\end{tabular}


TABLE VII

Distribution by Maternal Age for each SeX-Group: from Sample

\begin{tabular}{|c|c|c|c|c|c|c|c|c|}
\hline \multirow{2}{*}{ Age of Mother } & \multicolumn{2}{|c|}{$\mathbf{M M}$} & \multicolumn{2}{|c|}{ FF } & \multicolumn{2}{|c|}{ MF } & \multicolumn{2}{|c|}{ All } \\
\hline & No. & $\%$ & No. & $\%$ & No. & $\%$ & No. & $\%$ \\
\hline All Stated Ages & 413 & $100 \cdot 0$ & 677 & $100 \cdot 0$ & 312 & $100 \cdot 0$ & 1,402 & $100 \cdot 0$ \\
\hline $\begin{array}{c}\text { Under } 20 \\
20-24 \\
25-29 \\
30-34 \\
35-39 \\
40-44 \\
45 \text { and Over }\end{array}$ & $\begin{array}{r}4 \\
63 \\
129 \\
108 \\
90 \\
18 \\
1\end{array}$ & $\begin{array}{r}1 \cdot 0 \\
15 \cdot 3 \\
31 \cdot 2 \\
26 \cdot 2 \\
21 \cdot 8 \\
4 \cdot 4 \\
0 \cdot 2\end{array}$ & $\begin{array}{r}4 \\
76 \\
215 \\
188 \\
139 \\
50 \\
5\end{array}$ & $\begin{array}{r}0.6 \\
11 \cdot 2 \\
31 \cdot 8 \\
27.8 \\
20.5 \\
7.4 \\
0.7\end{array}$ & $\begin{array}{r}5 \\
26 \\
78 \\
108 \\
77 \\
18 \\
0\end{array}$ & $\begin{array}{r}1 \cdot 6 \\
8 \cdot 3 \\
25 \cdot 0 \\
34 \cdot 6 \\
24 \cdot 7 \\
5 \cdot 8 \\
-\end{array}$ & $\begin{array}{r}13 \\
165 \\
422 \\
404 \\
306 \\
86 \\
6\end{array}$ & $\begin{array}{r}0.9 \\
11 \cdot 8 \\
30 \cdot 1 \\
28 \cdot 8 \\
21 \cdot 8 \\
6.2 \\
0.4\end{array}$ \\
\hline
\end{tabular}

TABLE VIII

Distribution by Paternal Age for each Sex-Group: from Sample

\begin{tabular}{|c|c|c|c|c|c|c|c|c|}
\hline \multirow{2}{*}{ Age of Father } & \multicolumn{2}{|c|}{$\mathbf{M M}$} & \multicolumn{2}{|c|}{ FF } & \multicolumn{2}{|c|}{ MF } & \multicolumn{2}{|c|}{ All } \\
\hline & No. & $\%$ & No. & $\%$ & No. & $\%$ & No. & $\%$ \\
\hline All Stated Ages & 391 & $100 \cdot 0$ & 629 & $100 \cdot 0$ & 294 & $100 \cdot 0$ & 1,314 & $100 \cdot 0$ \\
\hline $\begin{array}{c}\text { Under } 20 \\
20-24 \\
25-29 \\
30-34 \\
35-39 \\
40-44 \\
45 \text { and Over }\end{array}$ & $\begin{array}{r}-\overline{28} \\
108 \\
108 \\
83 \\
45 \\
19\end{array}$ & $\begin{array}{r}\overline{7 \cdot 2} \\
27 \cdot 6 \\
27 \cdot 6 \\
21 \cdot 2 \\
11 \cdot 5 \\
4 \cdot 9\end{array}$ & $\begin{array}{r}-39 \\
163 \\
178 \\
140 \\
64 \\
45\end{array}$ & $\begin{array}{r}\overline{6 \cdot 2} \\
25 \cdot 9 \\
28 \cdot 3 \\
22 \cdot 3 \\
10 \cdot 2 \\
7 \cdot 2\end{array}$ & $\begin{array}{r}1 \\
15 \\
53 \\
95 \\
81 \\
34 \\
15\end{array}$ & $\begin{array}{r}0 \cdot 3 \\
5 \cdot 1 \\
18 \cdot 0 \\
32 \cdot 3 \\
27 \cdot 6 \\
11 \cdot 6 \\
5 \cdot 1\end{array}$ & $\begin{array}{r}1 \\
82 \\
324 \\
381 \\
304 \\
143 \\
79\end{array}$ & $\begin{array}{r}0 \cdot 1 \\
6 \cdot 2 \\
24 \cdot 7 \\
29 \cdot 0 \\
23 \cdot 1 \\
10 \cdot 9 \\
6 \cdot 0\end{array}$ \\
\hline
\end{tabular}

TABLE IX

Mean Age of Parents at Birth of Twins (In years)

\begin{tabular}{|c|c|c|c|c|}
\hline Parent & MM & FF & MF & All \\
\hline $\begin{array}{ll}\text { Mother } & \\
\text { Father .. }\end{array}$ & $\begin{array}{l}30 \cdot 94 \\
33 \cdot 44\end{array}$ & $\begin{array}{l}31 \cdot 60 \\
33 \cdot 93\end{array}$ & $\begin{array}{l}31 \cdot 99 \\
34 \cdot 45\end{array}$ & $\begin{array}{l}31 \cdot 50 \\
33 \cdot 90\end{array}$ \\
\hline
\end{tabular}

Table $\mathrm{V}$ gives the distribution by age and sex-group of our sample; Table VI shows the changes in the distribution of the sex-groups by age. There is a steady decline in the proportion of MM pairs with advancing age, and a compensating rise in FF pairs; the MF proportion shows comparatively small variation over the range of ages. Tables VII and VIII display the distributions of twins by age of mother and father respectively at birth of twins. The mean ages are summarized in Table IX, where apart from a difference of 2.4 years on the average there is no sensible divergence between maternal and paternal mean ages for the three sex-groups, each showing an increment of about half a year from MM to FF, and from FF to MF. In view of the lack of randomness, the wide and differentially distributed range of birth-years, and the small numbers, it is worthless to investigate further such a slight trend. 
The distributions by maternal and paternal ages differ little from one another, and neither differs materially from recent England and Wales distributions by maternal age, except that the like-sex peaks appear in the maternal age group 25-29 rather than in the group 30-34, and that the paternal age distributions show an expected displacement to the right of about $2 \frac{1}{2}$ years, and a slight degree of skewness to the right, also to be expected.

TABLE $X$

Distribution by Birth Rank for each Sex-Group: from SAmple

\begin{tabular}{|c|c|c|c|c|c|c|}
\hline \multirow{2}{*}{ Birth Rank } & \multicolumn{2}{|c|}{$\mathbf{M M}$} & \multicolumn{2}{|c|}{ FF } & \multicolumn{2}{|c|}{ MF } \\
\hline & No. & $\%$ & No. & $\%$ & No. & $\%$ \\
\hline $\begin{array}{r}1 \\
2 \\
3 \\
4 \\
5 \\
6 \\
7 \\
8 \\
9 \\
10 \\
11 \\
12 \\
13\end{array}$ & $\begin{array}{r}134 \\
135 \\
58 \\
23 \\
25 \\
13 \\
5 \\
5 \\
8 \\
3 \\
1 \\
1 \\
-\end{array}$ & $\begin{array}{r}32.6 \\
32 \cdot 8 \\
14 \cdot 1 \\
5.6 \\
6 \cdot 1 \\
3 \cdot 2 \\
1.2 \\
1.2 \\
1.9 \\
0.7 \\
0.2 \\
0.2 \\
-\end{array}$ & $\begin{array}{r}219 \\
172 \\
108 \\
59 \\
41 \\
25 \\
20 \\
17 \\
5 \\
3 \\
5 \\
2 \\
1\end{array}$ & $\begin{array}{r}32.3 \\
25.4 \\
16.0 \\
8.7 \\
6.1 \\
3.7 \\
3.0 \\
2.5 \\
0.7 \\
0.4 \\
0.7 \\
0.3 \\
0.2\end{array}$ & $\begin{array}{r}90 \\
76 \\
52 \\
33 \\
27 \\
19 \\
6 \\
3 \\
2 \\
2 \\
- \\
-\end{array}$ & $\begin{array}{r}29 \cdot 1 \\
24 \cdot 5 \\
16 \cdot 8 \\
10 \cdot 6 \\
8 \cdot 7 \\
6 \cdot 1 \\
1.9 \\
1.0 \\
0.6 \\
0.6 \\
= \\
-\end{array}$ \\
\hline Total (stated) & 411 & 100 & 677 & 100 & 310 & 100 \\
\hline Mean Rank & \multicolumn{2}{|c|}{$2 \cdot 61$} & \multicolumn{2}{|c|}{$2 \cdot 86$} & \multicolumn{2}{|c|}{$2 \cdot 85$} \\
\hline
\end{tabular}

In respect of birth rank (see Table $\mathrm{X}$ ), not available for England and Wales, the only feature of note is the lower mean rank of MM twins compared with either FF or MF. The greater proportion in the first two birth ranks among MM twins than among FF or MF is statistically significant, but it is difficult to assess whether this is an artefact of the sampling method. The numbers available do not admit of a useful breakdown, analogous to Table I, by both maternal age and birth rank simultaneously, nor of course does the Registrar-General tabulate the numbers of twin maternities by maternal age and previous children - or birth rank-separately for the three sex-groups. Though such a finding is by no means improbable, and is perhaps attributable at least in part to the higher sex ratio in early birth ranks, it is unlikely to be as large as here.

There were $307 \mathrm{MF}$ twin pairs for which we knew the order of birth, and they were distributed by age of mother as in Table XI and Fig. 5 (overleaf). Taken together they form a symmetrical distribution by maternal age, but, taken separately, although approximating closely at ages from 30 onwards, they differ for ages under 30 . Dividing them at age 30 into two age groups only, there are 23 more pairs in which the male was born first-a significant excess and one which is unlikely to be due to any of the factors disturbing the randomness of the sample. 
TABLE XI

Distribution by Maternal Age and Order of Birth for MF Twins: from SAmple

\begin{tabular}{|c|c|c|c|c|c|c|}
\hline \multirow{2}{*}{ Maternal Age Group } & \multicolumn{2}{|c|}{ M born First } & \multicolumn{2}{|c|}{ F born First } & \multicolumn{2}{|c|}{ Total MF } \\
\hline & No. & $\%$ & No. & $\%$ & No. & $\%$ \\
\hline All Stated Ages & 166 & $100 \cdot 0$ & 141 & $100 \cdot 0$ & 312 & $100 \cdot 0$ \\
\hline $\begin{array}{c}\text { Under } 20 \\
20-24 \\
25-29 \\
30-34 \\
35-39 \\
40-44\end{array}$ & $\begin{array}{r}2 \\
16 \\
47 \\
54 \\
40 \\
7\end{array}$ & $\begin{array}{r}0 \cdot 6 \\
5 \cdot 1 \\
15 \cdot 1 \\
17 \cdot 3 \\
12 \cdot 8 \\
2 \cdot 2\end{array}$ & $\begin{array}{r}3 \\
10 \\
29 \\
53 \\
36 \\
10\end{array}$ & $\begin{array}{r}1 \cdot 0 \\
3 \cdot 2 \\
9 \cdot 3 \\
17 \cdot 0 \\
11 \cdot 5 \\
3 \cdot 2\end{array}$ & $\begin{array}{r}5 \\
26 \\
78 \\
108 \\
77 \\
18\end{array}$ & $\begin{array}{r}1 \cdot 6 \\
8 \cdot 3 \\
25 \cdot 0 \\
34 \cdot 6 \\
24 \cdot 7 \\
5 \cdot 8\end{array}$ \\
\hline
\end{tabular}

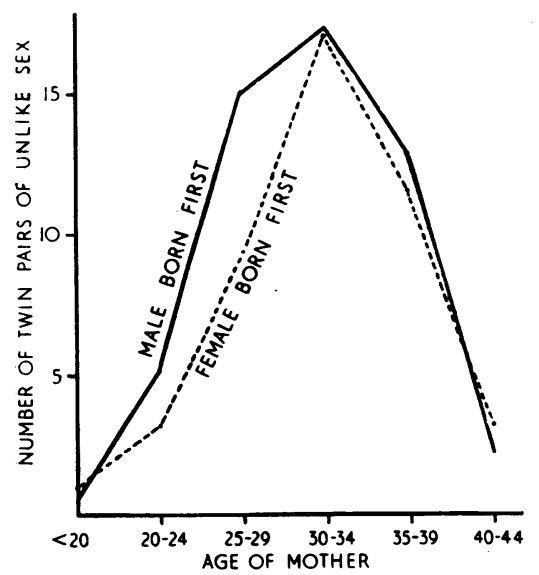

FIG. 5.-Twin pairs of unlike-sex, by age and by order of birth.

\section{Twin Relatives}

Twins who volunteered to co-operate were asked to give the names of other twins willing to take part in the investigation. In this way some related twin pairs were included in the sample, and must be excluded from certain tables, for example in arriving at estimates of familial incidence. Tables XII and XIII show for the three sex-groups separately the numbers and proportions of index cases with various numbers of twin relatives; related index cases are omitted from Table XII, and included in Table XIII. In this instance the results are scarcely affected by exclusion of related pairs.

Taking the figures for all sex-groups in Table XII as comprising a set using the maximum of information available without the bias introduced by including related index pairs, we have tried to fit Poisson distributions to the observed frequencies of twin relatives. Whether the Poisson frequencies are computed from the observed mean number of twin relatives, or from the zero group (obtaining the mean as the natural logarithm of the zero frequency), the distributions cannot be said to tally in any way, the observed frequencies being in excess of the predicted in the higher numbers of relatives for both methods of fitting. Precisely the same effect is found in fitting Poisson distributions by the two methods to the abridged distributions obtained by stepping down each number of relatives by one and starting with the second column as the new zero group; in doing this we regard the index cases not as twin-pairs for inclusion themselves but merely as selectors of a sample of families. It is very improbable, therefore, that the high frequencies of twin relatives are determined by the operation of chance alone, though of itself this result does not argue a genetic causation of twinning. 
TABLE XII

Number (and Percentage) of Index Twin Pairs with Twin Relatives: from Sample (excluding related index pairs)

\begin{tabular}{|c|c|c|c|c|c|c|c|c|c|c|c|c|c|c|}
\hline \multirow{3}{*}{$\begin{array}{c}\text { Sex-Group } \\
\text { of Index } \\
\text { Pair }\end{array}$} & \multicolumn{12}{|c|}{ Number of Sets of Twin Relatives } & \multirow{2}{*}{\multicolumn{2}{|c|}{ Total }} \\
\hline & \multicolumn{2}{|r|}{0} & \multicolumn{2}{|r|}{1} & \multicolumn{2}{|r|}{2} & \multicolumn{2}{|r|}{3} & \multicolumn{2}{|c|}{4} & \multicolumn{2}{|c|}{$5+$} & & \\
\hline & No. & $\%$ & No. & $\%$ & No. & $\%$ & No. & $\%$ & No. & $\%$ & No. & $\%$ & No. & $\%$ \\
\hline $\begin{array}{c}\text { MM } \\
\text { FF } \\
\text { MF }\end{array}$ & $\begin{array}{r}155 \\
214 \\
83\end{array}$ & $\left|\begin{array}{l}39 \cdot 4 \\
33 \cdot 0 \\
31 \cdot 2\end{array}\right|$ & $\begin{array}{r}118 \\
191 \\
89\end{array}$ & $\begin{array}{l}30 \cdot 0 \\
29 \cdot 4 \\
33 \cdot 5\end{array}$ & $\begin{array}{r}68 \\
129 \\
55\end{array}$ & $\mid \begin{array}{l}17 \cdot 3 \\
19 \cdot 9 \\
20 \cdot 7\end{array}$ & $\begin{array}{r}29 \\
71 \\
.25\end{array}$ & $\begin{array}{r}7 \cdot 4 \\
10 \cdot 9 \\
9 \cdot 3\end{array}$ & $\begin{array}{r}14 \\
25 \\
5\end{array}$ & $\begin{array}{l}3.6 \\
3.9 \\
1.9\end{array}$ & $\begin{array}{r}9 \\
19 \\
9\end{array}$ & \begin{tabular}{l|}
$2 \cdot 3$ \\
$2 \cdot 9$ \\
$3 \cdot 4$
\end{tabular} & $\begin{array}{l}393 \\
649 \\
266\end{array}$ & $\begin{array}{l}100 \\
100 \\
100\end{array}$ \\
\hline All & 452 & 34.55 & 398 & $30 \cdot 43$ & 252 & $19 \cdot 27$ & 125 & $9 \cdot 56$ & 44 & $3 \cdot 36$ & 37 & $2 \cdot 83$ & 1,308 & 100 \\
\hline
\end{tabular}

TABLE XIII

Number (and Percentage) of Index Twin Pairs with Twin Relatives: from Sample (including related index pairs)

\begin{tabular}{|c|c|c|c|c|c|c|c|c|c|c|c|c|c|c|}
\hline \multirow{3}{*}{$\begin{array}{c}\text { Sex-Group } \\
\text { of Index } \\
\text { Pair }\end{array}$} & \multicolumn{12}{|c|}{ Number of Sets of Twin Relatives } & \multirow{2}{*}{\multicolumn{2}{|c|}{ Total }} \\
\hline & \multicolumn{2}{|c|}{0} & \multicolumn{2}{|r|}{1} & \multicolumn{2}{|r|}{2} & \multicolumn{2}{|r|}{3} & \multicolumn{2}{|c|}{4} & \multicolumn{2}{|c|}{$5+$} & & \\
\hline & No. & $\%$ & No. & $\%$ & No. & $\%$ & No. & $\%$ & No. & $\%$ & No. & $\%$ & No. & $\%$ \\
\hline $\begin{array}{c}\text { MM } \\
\text { FF } \\
\text { MF }\end{array}$ & $\begin{array}{r}155 \\
214 \\
83\end{array}$ & $\begin{array}{l}37 \cdot 0 \\
31 \cdot 4 \\
26 \cdot 3\end{array}$ & $\begin{array}{r}123 \\
201 \\
99\end{array}$ & \begin{tabular}{l|}
$29 \cdot 4$ \\
$29 \cdot 5$ \\
$31 \cdot 4$
\end{tabular} & $\begin{array}{r}78 \\
137 \\
69\end{array}$ & $\begin{array}{l}18 \cdot 6 \\
20 \cdot 1 \\
21 \cdot 9\end{array}$ & $\begin{array}{l}36 \\
79 \\
39\end{array}$ & $\begin{array}{r}8 \cdot 6 \\
11 \cdot 6 \\
12 \cdot 4\end{array}$ & $\begin{array}{r}15 \\
26 \\
9\end{array}$ & $\begin{array}{l}3 \cdot 6 \\
3 \cdot 8 \\
2 \cdot 9\end{array}$ & $\begin{array}{l}12 \\
24 \\
16\end{array}$ & $\begin{array}{l}2 \cdot 9 \\
3 \cdot 5 \\
5 \cdot 1\end{array}$ & $\begin{array}{l}419 \\
681 \\
315\end{array}$ & $\begin{array}{l}100 \\
100 \\
100\end{array}$ \\
\hline All & 452 & $31 \cdot 94$ & 423 & $29 \cdot 89$ & 284 & $20 \cdot 07$ & 154 & $10 \cdot 88$ & 50 & $3 \cdot 53$ & 52 & $3 \cdot 67$ & 1,415 & 100 \\
\hline
\end{tabular}

Considering only twin pairs with twin sibs, we obtain the figures for the distribution by the number of pairs of twin sibs in the sibship, Table XIV; related index pairs are again excluded so that each family appears once only. The separation of families with two pairs of twin sibs into like-like (LL), like-unlike (LU), and unlike-unlike (UU) does not depart far from expectation calculated on a like to unlike ratio within the normal range though the UU group is deficient. Numbers, TABLE XIV

Distribution by Like- and Unlike-Sex of Sets of 2, 3, and 4 Twin Pairs in the same Sibship: FROM SAMPLE

\begin{tabular}{|c|c|c|c|c|c|c|}
\hline No. of Pairs & \multicolumn{4}{|c|}{ Types of Twin } & \multirow[t]{2}{*}{ Other* } & \multirow[t]{2}{*}{ Tota } \\
\hline \multirow{2}{*}{ Two } & $\mathbf{L L}$ & LU & UU & & & \\
\hline & 39 & 37 & 6 & - & 4 & 86 \\
\hline \multirow{2}{*}{ Three } & LLL & LLU & LUU & UUU & & \\
\hline & 2 & 5 & 3 & 3 & 2 & 15 \\
\hline \multirow{2}{*}{ Four } & LLLU & LLUU & UUUU & & & \\
\hline & 1 & 1 & 1 & - & 1 & 4 \\
\hline
\end{tabular}

* This heading includes half-sibs, sibs of unspecified sex-group, and one set of triplets. 
however, are small, and the bias of our sample constitutes a factor whose effect is difficult to assess, so that we cannot place much reliance on the results. Such a table on a larger scale, if it were available from national statistics for instance, would yield invaluable information about the randomness or otherwise of twinning of either kind among sibships already including one pair of twins.

We may further divide all the twin relatives included in Table XII into those related to their index pair on the maternal or paternal side, wherever this classification is applicable. Table XV shows the percentage related maternally for the three sex-groups, and for 1, 2,3, and 4t, sets of twin relatives. There is an increase in maternally-related twins as the number of sets of twin relatives increases, though the proportion for $4+$ is about equal to the mean for all numbers of relatives. This slight trend is not, however, statistically significant.

TABLE XV

Percentage of Twin Relatives related on Maternal Side to Index Pairs: from Sample

\begin{tabular}{|c|c|c|c|c|}
\hline \multirow{2}{*}{$\begin{array}{l}\text { No. of Sets of Twin } \\
\text { Relatives }\end{array}$} & \multicolumn{4}{|c|}{ Index Pairs } \\
\hline & $\mathbf{M M}$ & FF & $\cdot \quad \mathbf{M F}$ & All \\
\hline $\begin{array}{l}1 \\
2 \\
3 \\
4+\end{array}$ & $\begin{array}{l}50 \cdot 0 \\
59 \cdot 2 \\
64 \cdot 4 \\
55 \cdot 4\end{array}$ & $\begin{array}{l}49 \cdot 3 \\
55 \cdot 8 \\
64 \cdot 8 \\
61 \cdot 5\end{array}$ & $\begin{array}{l}55 \cdot 9 \\
55 \cdot 1 \\
71 \cdot 9 \\
52 \cdot 1\end{array}$ & $\begin{array}{l}51 \cdot 0 \\
56 \cdot 6 \\
66 \cdot 0 \\
57 \cdot 8\end{array}$ \\
\hline Total & 56.9 & $57 \cdot 9$ & $58 \cdot 6$ & $57 \cdot 7$ \\
\hline
\end{tabular}

TABLE XVI

Sex-Groups of Twin Relatives by Sex-Groups of Index Pairs: from Sample

\begin{tabular}{|c|c|c|c|c|c|}
\hline \multirow{2}{*}{ Index Pairs } & \multicolumn{5}{|c|}{ All Twin Relatives } \\
\hline & MM & $\mathbf{F F}$ & MF & Not Stated & Total \\
\hline $\begin{array}{c}\text { MM } \\
\text { FF } \\
\text { MF }\end{array}$ & $\begin{array}{r}119 \\
225 \\
80\end{array}$ & $\begin{array}{r}88 \\
205 \\
71\end{array}$ & $\begin{array}{r}125 \\
224 \\
97\end{array}$ & $\begin{array}{r}113 \\
227 \\
95\end{array}$ & $\begin{array}{l}445 \\
881 \\
343\end{array}$ \\
\hline All & 424 & 364 & 446 & 435 & 1,669 \\
\hline
\end{tabular}

TABLE XVII

Percentage Distribution of Sex-Groups of Twin Relatives, by Sex-Group of Index Pair WITH LIKE/UNLIKE RATIO

\begin{tabular}{c|c|c|c|c|c|c}
\hline \multirow{3}{*}{ Index Pairs } & \multicolumn{9}{|c}{ All Twin Relatives } & \multicolumn{1}{c}{} \\
\cline { 2 - 7 } & MM & FF & MF & Total Stated & Not Stated & L/U \\
\hline MM & $35 \cdot 8$ & $26 \cdot 5$ & $37 \cdot 7$ & 100 & $25 \cdot 4$ & $1 \cdot 656$ \\
FF & $34 \cdot 4$ & $31 \cdot 3$ & $34 \cdot 3$ & 100 & $25 \cdot 8$ & 1.920 \\
MF & $32 \cdot 3$ & $28 \cdot 6$ & $39 \cdot 1$ & 100 & $27 \cdot 7$ & $1 \cdot 557$ \\
\hline All & $34 \cdot 4$ & $29 \cdot 5$ & $36 \cdot 1$ & 100 & $26 \cdot 1$ & $1 \cdot 767$ \\
\hline
\end{tabular}


Tables XVI and XVII show respectively by numbers and percentage the sex group of all twin relatives against the sex-group of index pairs. In Table XVII, the percentages in the three sex-groups of relatives are calculated on the totals of stated sex-group only, while the percentages of " not stated" are based on the totals of all relatives. The constancy of the proportion of sex-group " not stated ", notwithstanding its irrelevancy to the issue, is very striking, and similar internal consistencies are apparent from other tables. Though not directly very informative, they may perhaps indicate a certain homogeneity in our sample despite its initial lack of randomness.

The twins shown in Table XVI are relatives respectively of $238 \mathrm{MM}, 435 \mathrm{FF}$, and $183 \mathrm{MF}$ index pairs, with a like to unlike $(\mathrm{L} / \mathrm{U})$ ratio of $3 \cdot 678$, slightly in excess of that for all index pairs (3.492). Table XVII gives the L/U ratio of the twin relatives for each sex-group of the index pairs. For all sex-groups the ratio is 1.767 , the figure also obtained for all live-born twins in the $10 \frac{1}{2}$-year period, 1938-48 (England and Wales). Taken in conjunction with the proportions shown in the body of the table these figures suggest that although the index pairs deviate from normality, their twin relatives are distributed among the sex-groups in accordance with the distribution in the general population. Though numbers are not large enough to make the observation statistically significant, it may be noted that the highest proportion of MM relatives is associated with $M M$ index pairs, and likewise for FF and MF index pairs.

Relatives of index pairs have been classified according to the type of relationship. There were twelve index pairs whose mothers and thirteen whose fathers were twins, neither figure being in excess of the expectation of twins in a sample of similar size. FF index pairs possess slightly (though insignificantly) fewer twin sibs than $\mathrm{MM}$ or MF, and twin sibs of all index pairs show a low $\mathrm{L} / \mathrm{U}$ ratio of $1 \cdot 36$, due to a deficiency of FF twin sibs of all three index groups. Among aunts and uncles there is again an excess of FF index pairs and a deficiency of FF aunts of each index group (see Table XVIII). Divided into those related maternally or paternally to an index pair this gives a total of 61.6 per cent. maternally related, a proportion which rises to 69 per cent. in the MF column and which is reproduced among each index

TABLE XVIII

Distribution for Each Index-Pair Sex-Group of Twin Aunts and Uncles by Sex-Groups

\begin{tabular}{|c|c|c|c|c|c|c|c|c|}
\hline \multirow{3}{*}{ Index Pairs } & \multicolumn{8}{|c|}{ Aunts and Uncles } \\
\hline & \multicolumn{2}{|c|}{ MM } & \multicolumn{2}{|c|}{ FF } & \multicolumn{2}{|c|}{ MF } & \multicolumn{2}{|c|}{ All } \\
\hline & $m$ & $p$ & $m$ & $p$ & $m$ & $p$ & $m$ & $p$ \\
\hline $\begin{array}{l}\text { MM } \\
\text { FF } \\
\text { MF }\end{array}$ & $\begin{array}{r}6 \\
25 \\
10\end{array}$ & $\begin{array}{r}11 \\
14 \\
5\end{array}$ & $\begin{array}{r}4 \\
21 \\
6\end{array}$ & $\begin{array}{r}6 \\
15 \\
4\end{array}$ & $\begin{array}{l}13 \\
33 \\
12\end{array}$ & $\begin{array}{r}5 \\
15 \\
6\end{array}$ & $\begin{array}{l}23 \\
79 \\
28\end{array}$ & $\begin{array}{l}22 \\
44 \\
15\end{array}$ \\
\hline All & 41 & 30 & 31 & 25 & 58 & 26 & 130 & 81 \\
\hline
\end{tabular}

Related maternally $(m)$; related paternally $(p)$. 
group. Twin grandparents are lacking in FF pairs but include more MF pairs: otherwise they divide evenly between maternal and paternal sides, and are distributed among the index groups in the same proportions as for the whole sample.

Cousins who are twins have been divided according as they are children of the index pair's mother's sister, mother's brother, father's sister, or father's brother; the total numbers falling into these categories are respectively $68,46,66$, and 45 , which are distributed among the index groups as in Table XIX. From this table it is evident that a similar distribution obtains within each index group to that of all groups, showing an excess of twin cousins among the children of sisters of either parent of an index pair. Any real differential between the four types of cousin relationship would be expected to affect the distaff side (mother's sister) as against the spear side (father's brother), the other two types (mother's brother, father's sister) forming a reciprocal intermediate relationship according to which of two pairs of twin cousins is regarded as the index pair.

TABLE XIX

Twin Cousins by Type of Relationship to Index Pairs

\begin{tabular}{|c|c|c|c|c|c|}
\hline \multirow{3}{*}{ Index Pairs } & \multicolumn{4}{|c|}{ Twins' Cousins are Children of: } & \multirow{3}{*}{ Total } \\
\hline & \multicolumn{2}{|c|}{ Mother's } & \multicolumn{2}{|c|}{ Father's } & \\
\hline & Sister & Brother & Sister & Brother & \\
\hline $\begin{array}{c}\text { MM } \\
\text { FF } \\
\text { MF }\end{array}$ & $\begin{array}{l}20 \\
35 \\
13\end{array}$ & $\begin{array}{l}10 \\
25 \\
11\end{array}$ & $\begin{array}{l}15 \\
36 \\
15\end{array}$ & $\begin{array}{l}12 \\
23 \\
10\end{array}$ & $\begin{array}{r}57 \\
119 \\
49\end{array}$ \\
\hline All & 68 & 46 & 66 & 45 & 225 \\
\hline
\end{tabular}

TABLE XX

Relationship between Parents of Twin Cousins

\begin{tabular}{|c|c|c|c|c|c|c|c|c|c|c|c|c|}
\hline \multirow{2}{*}{ Index Pairs } & \multicolumn{4}{|c|}{ Sisters } & \multicolumn{4}{|c|}{ Brother-Sister } & \multicolumn{4}{|c|}{ Brothers } \\
\hline & $\mathbf{M M}$ & FF & MF & Total & MM & FF & MF & Total & MM & FF & MF & Total \\
\hline $\begin{array}{l}\text { MM } \\
\text { FF } \\
\text { MF }\end{array}$ & $\begin{array}{r}5 \\
11 \\
7\end{array}$ & $\begin{array}{l}4 \\
9 \\
2\end{array}$ & $\begin{array}{r}6 \\
12 \\
4\end{array}$ & $\begin{array}{l}15 \\
32 \\
13\end{array}$ & $\begin{array}{l}3 \\
9 \frac{1}{2} \\
2 \frac{1}{2}\end{array}$ & $\begin{array}{l}2 \\
7 \\
3\end{array}$ & $\begin{array}{c}6 \\
11 \frac{1}{2} \\
5 \frac{1}{2}\end{array}$ & $\begin{array}{l}11 \\
28 \\
11\end{array}$ & $\begin{array}{l}2 \\
7 \\
1\end{array}$ & $\begin{array}{l}3 \\
6 \\
6\end{array}$ & $\begin{array}{l}4 \\
6 \\
3\end{array}$ & $\begin{array}{r}9 \\
19 \\
10\end{array}$ \\
\hline All & 23 & 15 & 22 & 60 & 15 & 12 & 23 & 50 & 10 & 15 & 13 & 38 \\
\hline
\end{tabular}

Including only those twin cousins for which we possess complete information respecting sex-group and type of relationship, we obtain Table $\mathrm{XX}$, which is set out in terms of the relationship between the parents of twin cousins. In the central (brother-sister) section appear the mean figures for the two relationships to index pairs (via mother's brother and father's sister); this has been done to facilitate direct comparison with the other two sections, and explains the appearance of fractions. For each index group as for the total, there is a decline in numbers from the distaff to the spear side, and the $\mathrm{L} / \mathrm{U}$ ratio for index pairs also declines in the 
same direction, though among the cousins of index pairs the $\mathrm{L} / \mathrm{U}$ ratio is highest in the " brothers" section (1.9), and lowest in the " brother-sister" section $(1 \cdot 2)$. These differences are not statistically significant and it would require a much larger sample to establish the trends. Davenport (1920) and Greulich (1934) each obtained results also seemingly anomalous in the order in which the types of cousin relationship were ranked, though the order sometimes differs from ours. This probably arises from a similar insufficiency of numbers.

Of parents of index pairs, six were first cousins and six second cousins; two others were more distantly related. The incidence of marriage between first cousins is slightly below the average (about 0.4 per cent. against 0.7 per cent.) but not significantly so; certainly it is not indicative of any simple mode of inheritance of twinning.

TABLE XXI

Interval between Birth of Each Child in a Twin Pair, by Sex-Group

\begin{tabular}{|c|c|c|c|c|c|c|c|c|c|c|c|c|c|}
\hline \multirow{3}{*}{ Sex-Group } & \multicolumn{12}{|c|}{ Interval (hours) } & \multirow{2}{*}{ Total } \\
\hline & \multicolumn{2}{|c|}{$<1$} & \multicolumn{2}{|c|}{$1-$} & \multicolumn{2}{|c|}{2} & \multicolumn{2}{|c|}{$3-$} & \multicolumn{2}{|c|}{4} & \multicolumn{2}{|c|}{$5+$} & \\
\hline & No. & $\%$ & No. & $\%$ & No. & $\%$ & No. & $\%$ & No. & $\%$ & No. & $\%$ & No. $\%$ \\
\hline $\begin{array}{l}\text { MM } \\
\text { FF } \\
\text { MF }\end{array}$ & $\begin{array}{l}310 \\
525 \\
201\end{array}$ & $\begin{array}{l}77 \cdot 7 \\
80 \cdot 4 \\
67 \cdot 9\end{array}$ & $\begin{array}{l}51 \\
76 \\
49\end{array}$ & $\begin{array}{l}12.8 \\
11.6 \\
16.6\end{array}$ & $\begin{array}{l}14 \\
26 \\
16\end{array}$ & $\begin{array}{l}3 \cdot 5 \\
4 \cdot 0 \\
5 \cdot 4\end{array}$ & $\begin{array}{r}7 \\
5 \\
13\end{array}$ & $\begin{array}{l}1 \cdot 8 \\
0.8 \\
4 \cdot 4\end{array}$ & $\begin{array}{l}5 \\
5 \\
8\end{array}$ & $\begin{array}{l}1 \cdot 2 \\
0 \cdot 8 \\
2 \cdot 7\end{array}$ & $\begin{array}{r}12 \\
16 \\
9\end{array}$ & $\begin{array}{l}3 \cdot 0 \\
2 \cdot 4 \\
3 \cdot 0\end{array}$ & $\begin{array}{ll}399 & 100 \\
653 & 100 \\
296 & 100\end{array}$ \\
\hline All & 1,036 & $76 \cdot 9$ & 176 & $13 \cdot 0$ & 56 & $4 \cdot 2$ & 25 & $\cdot 1 \cdot 8$ & 18 & $1 \cdot 3$ & 37 & $2 \cdot 8$ & $1,348 \quad 100$ \\
\hline $\begin{array}{l}\text { Total Like- } \\
\text { sex Pairs }\end{array}$ & 835 & $79 \cdot 4$ & 127 & $12 \cdot 1$ & 40 & $3 \cdot 8$ & 12 & $1 \cdot 1$ & 10 & $1 \cdot 0$ & 28 & $2 \cdot 6$ & $1,052 \quad 100$ \\
\hline
\end{tabular}

The time interval between the birth of each twin of a pair (Table XXI) was less than one hour for about three-quarters of the sample. The times are tabulated in successive hourly intervals from less than one hour to five or more hours, the range in this last group extending to a maximum of four days. There is no significant difference between the intervals for the two types of like-sex pairs, which are shown grouped together at the bottom of the table, but a very significant difference $(t>4)$ exists between like-sex and unlike-sex pairs in respect of the proportions less than one hour. It is also evident from the increased proportions in each period of more than an hour that the interval between the births of twins of unlike sex is greater than that for like-sex twins. Whether this is due to the difference in sex or to the different origins of monozygous and dizygous twins it is impossible at this juncture to determine.

\section{Children OF Twins}

From married twins of our sample we requested the age, sex, birth dates, and age of the mother at the birth in respect of any children. Table XXII shows that a greater number of twins is born to mothers who are themselves twins, though fathers who are twins have no more than the expected number for the general population (1.2 per cent. approximately). From the high rate among mothers known to be dizygous twins (11 twin-pairs in 122 maternities) we may infer with 
considerable confidence that it is dizygous twinning which shows this hereditary effect. If the like-sex twins are a random sample of monozygous and dizygous origins, about three-fifths should be dizygous, so that the rate may be expressed as approximately thirteen twin pairs in 300 maternities of dizygous mothers (reducing the fifteen to thirteen twin pairs, allowing two to 200 maternities of monozygous mothers). This rate does not equal that in mothers who are members of MF pairs, but we have some reason to suppose our like-sex twin index pairs overweighted with monozygous twins, so that the approximate rate given above errs on the conservative side.

The mean number of maternities per family (sibship) remains very constant between the index-pair sex-groups (Table XXII), so that the proportions are not due to gross differences in size of family. A discrepancy between the numbers of the sexes of the single children is traceable to the children of families where the mother is a twin; the deficiency of female children is, however, not statistically significant.

TABLE XXII

Distribution of Children of Index Pairs

\begin{tabular}{|c|c|c|c|c|c|c|c|c|c|c|c|c|c|}
\hline \multirow{2}{*}{\multicolumn{2}{|c|}{$\begin{array}{c}\text { Index } \\
\text { Pair }\end{array}$}} & \multirow{2}{*}{$\begin{array}{l}\text { No. of } \\
\text { Sibships }\end{array}$} & \multicolumn{4}{|c|}{ Single Births } & \multicolumn{5}{|c|}{ Twin Births } & \multirow{2}{*}{$\begin{array}{c}\text { Total } \\
\text { Materni- } \\
\text { ties }\end{array}$} & \multirow{2}{*}{$\begin{array}{l}\text { Mean No. } \\
\text { of Materni- } \\
\text { ties per } \\
\text { Sibship }\end{array}$} \\
\hline & & & $\mathbf{M}$ & $\mathbf{F}$ & $\begin{array}{c}\text { Un- } \\
\text { specified }\end{array}$ & Total & $\mathbf{M M}$ & FF & MF & $\begin{array}{c}\text { Un- } \\
\text { specified }\end{array}$ & Total & & \\
\hline \multicolumn{2}{|c|}{$\mathbf{M M}$} & 132 & 128 & 123 & 2 & 253 & - & 2 & 2 & - & 4 & 257 & $1 \cdot 95$ \\
\hline \multicolumn{2}{|l|}{ FF } & 260 & 269 & 225 & 2 & 496 & 4 & 5 & 5 & 1 & 15 & 511 & 1.97 \\
\hline \multirow{2}{*}{ MF } & $\mathbf{M}$ & 35 & 28 & 37 & - & 65 & 1 & - & - & - & 1 & 66 & $1 \cdot 89$ \\
\hline & $\mathbf{F}$ & 60 & 63 & 48 & - & 111 & 3 & 3 & 5 & - & 11 & 122 & $2 \cdot 03$ \\
\hline \multicolumn{2}{|c|}{ All } & 487 & 488 & 433 & 4 & 925 & 8 & 10 & 12 & 1 & 31 & 956 & $1 \cdot 96$ \\
\hline
\end{tabular}

\section{Conclusions}

The figures published by the Registrar-General and obtained from the augmented information available since 1938 from birth certification now cover a period of $10 \frac{1}{2}$ years in England and Wales. They enable us to examine the incidence of twinning by maternal age and, to a degree of approximation, by birth rank; and to estimate also the effects of maternal age separately on the proportions of monozygous and dizygous twins, and of triplets. In agreement with other published studies we find that monozygous twinning is virtually unaffected by maternal age, and that dizygous twinning ranges in frequency by maternal age from less than half to more than four times the rate for monozygous. If we discount, as seems plausible, the direct effects of any external environmental agency in its causation, the variation in the dizygous rate must be due, at least in part, to physiological factors changing with age the internal environment of the reproductive organs.

We can only deal with aggregate figures from national statistics yielding sufficient weight of numbers to support such investigation; we cannot tell except 
inadequately of the effects among individuals. A slight extension of the present requirements at birth registration to include:

(1) the number of previous maternities, in addition to the number of previous children;

(2) the specification by sex-groups of any previous multiple maternities;

(3) whether or not either parent is a twin, and if so the sex of the co-twin;

would permit a much more useful analysis of twin production to be made.

Our sample survey was undertaken in an attempt to supplement the deficiencies of national statistics; many of the results were inconclusive. Some of the gains in detail were offset by lack of randomness in the distribution, though often the size of subsamples would have rendered results indecisive even had a random over-all distribution obtained. The results of enquiry into the relationship, before marriage, between the parents of twins upheld our suspicion that no simple genetic explanation would be forthcoming from that source. If the outcome of our further task to establish criteria for the accurate diagnosis of zygosity is successful, a reexamination of our data grouped into monozygous and dizygous rather than like and unlike may bear more fruit.

Much more valuable information on the inheritance of twinning was provided by an analysis of the offspring of married index pairs, which revealed that the rate of twin-production is significantly increased among mothers who are themselves twins. Almost unequivocally we may say that a tendency to dizygous twinning is inherited through the female line-that women who are members of dizygous twin pairs are several times more likely to give birth to dizygous twins. Though the twinning rate in families where the father is a member of a twin pair of either type is not increased above its value in the general population, it is at least plausible that the effect is sex-limited, i.e. that its exhibition is confined to the female, in the form of binovulation, but that the male may transmit the factor or factors responsible for the condition, to be exhibited in a female descendant.

\section{SUMMARY}

A. Analysis of Data from the Registrar-General's Annual Statistical REVIEWS FOR ENGLAND AND WALES, 1938-48

(1) The results of $10 \frac{1}{2}$ years' operation of the Population (Statistics) Act, 1938, analysed simultaneously by maternal age and number of previous children (not precisely birth rank) for rates of twinning, show for each number of previous children the familiar curve of incidence by age with a maximum rate in the maternal age group 35-39.

(2) In each maternal age group the twinning rate increases with the number of previous children up to the 8th or 9th birth rank-assuming the approximate equivalence between the number of previous children and the birth rank.

(3) Weinberg's method, the simplest for effecting separation into monozygous and dizygous twins, gives results which differ very slightly from others possessing superior theoretical credentials. 
(4) Weinberg's method is used to give age incidence of monozygous and dizygous twinning. The rate of monozygous twinning remains sensibly constant at about three maternities per thousand at different maternal ages; the rate of dizygous twinning varies with maternal age, being less than half the monozygous rate at age 16 and more than four times at ages 35-39.

(5) For each maternal age group, excepting the extremities of the range, the incidence of triplet maternities adheres closely to Hellin's law, allowing for a nearly constant factor of proportionality representing an increased mortality rate.

\section{B. Analysis of Familial Material from a Sample of 1,415 Twin Pairs who CO-OPERATED VOLUNTARILY IN RESPONSE TO AN APPEAL}

(1) Replies to a questionnaire from 1,415 twin pairs were available for analysis. The distribution of MM, MF, and FF pairs was not random.

(2) Of unlike-sex pairs, the male is more frequently born first if the mother is aged under 30 , but after 30 there is no preference. The time interval between the births of the two members of a twin pair is significantly greater in unlike-sex than in like-sex twins.

(3) The evidence suggests that twins are more common among relatives of twins than in the general population.

(4) Among twin relatives of index pairs, more are related on the maternal sidean effect which is considerably more pronounced for related twins of unlike sex, particularly among aunts and uncles. Cousins who are twins do not show any very significant preference among their four possible types of relationship to an index pair.

(5) An analysis of the offspring of parents one of whom is a twin shows a much increased rate of dizygous twin production among females who are members of dizygous pairs, although the rate among the children of male twins does not differ from that in the general population.

This investigation was assisted by a grant from the Birmingham University Students' Social Services Fund.

I wish to acknowledge particularly the assistance of Miss A. Vallier in the preparation of the material for this paper, and also to express my gratitude for the help of Miss Gwenda Griffith and Miss Jean Smith.

\section{REFERENCES}

Davenport, C. B. (1920). Amer. Nat., 54, 122.

Greulich, W. W. (1934). Amer. J. phys. Anthrop., 19, 391.

Hellin, D. (1895). "Die Ursache der Multiparität der Unipaaren Tiere überhaupt und der Zwillingsschwangerschaft beim Menschen ". München.

Komai, T., and Fukuoka, G. (1932). Z. Morph. Anthrop., 31, 167.

Jenkins, R. L. (1927). J. Hered., 18, 387.

Jenkins, R. L., and Gwin, J. (1940). Ibid., 31, 243.

Registrar-General's Statistical Reviews of England and Wales (1938-48), Tables. Part II: Civil. - (1938-39). Text.

Weinberg, W. (1909). Arch. Rass.- und GesBiol., 6, 322.

Yerushalmy, J., and Sheerar, S. E. (1940). Hum. Biol., 12, 95. 